\title{
Prasanta Chandra Mahalanobis and the Beginning of the Indian Statistical Institute
}

\author{
Samir Kumar Saha* \\ (Received 10 April 2018; revised 9 May 2018)
}

\begin{abstract}
Prasanta Chandra Mahalanobis (1893-1972) was one of the scientists of Colonial India who transited from Physics to Statistics to Economic Planning in Independent India. In this article, his B N Seal connection is traced to show his transition to Statistics; as also his Tagore connection, his worldview and networking to build world class institute, the Indian Statistical Institute (ISI). The early days of the ISI from the Physics Laboratory of the Presidency College to Baranagore, its present address is briefly chronicled. The contribution of his national compatriots like R C Bose, C R Rao and his international networking with R A Fisher, Shewhart and other stalwarts and his election as Fellow of Royal Society is described. Finally, an effort has been made to show his Nehru connection and transition to economic planning, particularly $2^{\text {nd }}$ Five Year Plan of India and how it added to growth of ISI.
\end{abstract}

Key words: Brajendra Nath Seal, FRS, Indian Statistical Institute, Large scale sample survey, Mahalanobis distance, Prasanta Chandra Mahalanobis, Presidency College, R A Fisher, Rabindranath Tagore, Second Five Year Plan, Statistics.

\section{Introduction: Geneology and Education}

Born in Kolkata on $29^{\text {th }}$ June, 1893 in an aristocratic family which was close to Tagore and Brahmo Samaj, Prasanta Chandra was influenced by both Rabindranath and Brahmo Samaj which must have shaped his broad, universal outlook. Not fighting colonialists in the political way, he built up an international level institute and later, in independent India, was instrumental in framing the national plan for fast rate of growth - though economic planning was not his specialisation. This short article attempts to bring out the multiple facets of a scientist, who was deeply in love with his country and was an expert in networking for institution building.

Prasanta Chandra Mahalanobis, (henceforth PCM), had his early education in Brahmo Boy's School, doing his Entrance Exam. in 1908.
Then he joined Presidency College, did his Intermediate in 1910 ( $11^{\text {th }}$ position $)$ and B.Sc. with Physics ( $2^{\text {nd }}$ Class) in 1912. In 1913, he left for studying science in London but a visit to Cambridge, made him decide to study at King's College, where he got admission in October, 1913. He passed Tripos Part-I in Mathematics and qualified in Tripos Part-II in Natural Sciences subsequently in 1914 and 1915, getting $1^{\text {st }}$ Class in Tripos II. A research scholarship was awarded to him to work in Cavendish Laboratory in Physics. However, coming back to India for a vacation, he never went back. He found engaging problems in India that needed solutions (Rao, 1973).

\section{The Ramanujan Connection}

How profound was the impact of $S$ Ramanujan on PCM, can not be ascertained except

\footnotetext{
* Formerly, Professor, Mechanical Engg., Jadavpur University and presently Professor, Mech. Engg. - MCKVIE, Liluah, Howrah -711204, E-mail : sahasamir7@gmail.com
} 
PCM's own words (Mahalanobis, 1993) 'he made a lasting impression on my mind.'

PCM was in King's College when Ramanujan entered the Trinity College under $G$ $\mathrm{H}$ Hardy's mentorship to work on Theory of Numbers (we will later find one important mentor of PCM, B N Seal also did important work on theory of numbers). Again, to quote PCM, 'On Sunday mornings Ramanujan and I went out for long walks'. PCM did write down points they discussed.

Amongst the discussions, Ramanujan's concept of zero (negation of all attributes) and infinity (the totality inexhaustible attributes) and that their product is able to supply the whole set of finite numbers had a lasting impression on PCM's mind.

Later, PCM deeply studied the foundations of Indian logic and traced the root of this concept to the Indian - Jaina theory of $S y \bar{a} d v \bar{a} d a$, the dialectic of sevenfold theory of knowledge in his paper on 'Philosophical basis of Statistics' (Mahalanobis, 1954).

\section{Transition to Statistics}

After Tripos Part-II, PCM spent a considerable time in the library of King's College. It was there, he was introduced to the statistical journal, Biometrika (edited by Karl Pearson) and the Biometric tables by his tutor W H Macaulay. PCM got interested in these and purchased sets to bring back with him during his journey back to India. Study of these journals are one amongst many things that made possible his transition from Physics to Statistics.

\section{As C R Rao narrates,}

He saw that statistics was ... capable of wide application. He tried to look for problems ... found some extremely interesting problems in meteorology and anthropology ... This was the turning point in his scientific career.

\section{Presidency College and PCM}

PCM joined Presidency College as a teacher of Physics in 1916 and stayed a long thirtythree years there. He was made Professor in 1922 under IES and also became the Head of the Physics Department. Amongst his compatriots were M N Saha and S N Bose - who became two of the most famous physicists in India and also in the world.

However Saha went away to Allahabad for a while and S N Bose went to Dhaka for sometime, while Mahalanobis did not. He went on carrying his statistical journey from Presidency itself, founded the Indian Statistical Institute in Presidency and also became the principal of the Presidency College from 1945-1948 (Mahalanobis, 1983, p.13).

In Presidency, he taught hydrostatics at UG level and relativity at PG Level. He was not a conventional teacher following text books. He was also inaccessible to students. However, it was during this period he wrote the historical introduction to the book 'Principles of Relativity' - a translation of original papers of Einstein and Minkwaski by M N Saha and S N Bose and published by the Calcutta University in 1920. So, one can presume, his reputation in Physics was established.

\section{Marriage, Brahmo Samaj and Tagore Connection}

During the period 1915 to 1923 , three very important things happened in the life of PCM. The first was the initiation of his long courtship with Nirmal Kumari Maitra, daughter of Heramba Chandra Maitra, and an orthodox leader of Brahmo Samaj. The second, his academic interaction with Prof. Brajendra Nath Seal in a Calcutta University examination review committee set up by Sir Asutosh Mukherjee in 1917. And then his deep involvement in Brahmo Samaj and propagation for Rabindranath Tagore's election to Brahmo Samaj in 1921. 
Ethical and legal issues did not allow Herambachandra to give consent to Nirmal Kumari's marriage to PCM. After long discussions he yielded but was not present during the marriage, which took place on February, 1923, in presence of her maternal uncle, Sir Nilratan Sircar. Tagore was also present.

Nirmal Kumari (or Rānī as she was called), a close associate of Tagore was a devoted wife and created a moderating influence on PCM's busy, impatient life by keeping him worry free from household chores. She also accompanied him on many international tours with Tagore and chronicled the details. During the ISI days also, Nirmal Kumari stood like a rock beside PCM and took care of the international guests.

Tagore's ideals and universalism influenced PCM very strongly. His association with Tagore started in 1911 (Mahalanobis, 1983, p. 25), and PCM was first made a founder member of Asramika Sangha in 1913, was involved in writing the draft statutes of the Visva-Bharati from 1918 to 1921 , and was present during the inauguration of the Visva-Bharati on $22^{\text {nd }}$ December, 1921. The inaugural speech was given by Prof. B N Seal. PCM remained the Jt. Secretary of Visva-Bharati from 1921-1931, long ten years. It must also be mentioned here that he was the one to see the first draft of Rabindranath's letter to the Viceroy of India on May 31, 1919, relinquishing his knighthood to protest against Jalianwallabagh Massacre. His pamphlet written on $15^{\text {th }}$ March, 1921, 'Why we want Rabindranath', for election of Rabindranath to Brahmo Samaj, clearly explains Tagore's concept of universal humanism unbounded by national boundaries.

The Tagore - PCM relation was a very strong bond and it may be said here the concept 'Statistics has a purpose' was an embryo of PCM's strong devotion to Tagore's ideals.

\section{The B N Seal Connection}

One other personality who greatly influenced PCM was Prof. Brajendra Nath Seal
(B N Seal) who was a Professor of Philosophy at Calcutta University. All through his life, PCM acknowledges this debt again and again.

In a letter to B N Seal dated $2^{\text {nd }}$ June, 1935 (Rudra, 1996, p. 128), PCM writes,

... In your address before the Races Congress ... (was it in 1911 or earlier?) you have pointed out very clearly and emphatically the need of using ndimensional hyperspace for representation of racial types. ... your idea was the starting point of my own work on the Generalised distance between Statistical groups.

In the paper on the 'United Province Anthropometric Survey, 1941' PCM wrote, '... the idea of such a geometrical representation was explicitly formulated by the late Sir Brajendra Nath Seal in an address on Race origin delivered before the first Universal Races Congress in London in 1911' (Rudra,1996, p.196). PCM clearly states in the earlier letter I owe to you the entire background of my statistical knowledge especially in its logical aspects ...'(Rudra, 1996, p.128).

PCM also states,

My first introduction to statistical analysis (in its modern/mathematical sense) was in connection with your work on the percentage of passes in the Calcutta University, which you have taken up as a member of the Special Committee appointed by the University for this sometime about 1916. ... I was in touch with the actual computational work. ... this report of yours was never published though more than 300 pages of foolscap galley-proof had been corrected by you and me.

It is also found how B N Seal guides PCM. In a letter dated $23^{\text {rd }}$ May, 1917, B N Seal writes to PCM (Rudra,1995, p. 127):

\footnotetext{
... As to correlation use Karl Pearson's though this is not good for the matter in hand ... The table of correlation ... need not be attempted at all.
}

This report contained, frequency distribution of marks, correlation between marks, percentage of passes in different years etc. of Calcutta University exams. This definitely involved lot of statistical computation. 
About B N Seal, he was a Professor of Philosophy but tracing back, it can be found that he had to his credit, a great deal of mathematical work.

He wrote, Memoir on the coefficients of Numbers, being a chapter in the Theory of Numbers (Calcutta, Hare Press, 1891)' when he was principal, Berhampore College, Bengal (Royal Asiatic Society Proceedings, 1892, p.397). Also, we find that in his paper Meaning of Race, Tribe, Nation', in the First Universal Races Congress, 1911 in London University he talks about going beyond 2-dimensions to talk about racial characteristic analysis (Seal, 1911). B N Seal was then principal of Coochbehar College, Bengal. It is clear, B N Seal left a permanent imprint in PCM's life.

\section{The Statistical Lab at Presidency College, establishment OF ISI AND STARTING OF THE JOURNAL $\boldsymbol{S}_{A N K H Y \bar{a}}$}

As PCM was teaching Physics, he parallely started doing research and project works in Statistics. He set up a 'Statistical Laboratory' at the Physics Department of the Presidency College in 1920s and from 1928, it started functioning from the Baker Laboratory in the same Department (Ghosh, Maiti and Bera, 2011, pp.1011-1054).

The establishment of the Statistical Laboratory was preceded and followed by a flurry of activities for PCM: a) 1922 floods in North Bengal and 1926 floods in Orissa led to his statistical studies of rainfall and floods in Orissa for 60 years, and further, the provincial govts. of Bihar and Orissa requested him to prepare report on rainfall and floods in Orissa; b) PCM's publication on Agricultural Field Trials just after R A Fisher's work in same area got him connected with R A Fisher, which lasted till Fisher's demise; c) The Imperial Council of Agriculture Research (ICAR) established at India by advice of Royal
Commission of Agriculture, British Govt. and R A Fisher in 1929; d) ICAR granted money for continuation of statistical works of PCM (A.M.)

All these finally lead to the establishment of Indian Statistical Institute as a registered society in 1931, with Sir R N Mukherjee as President and PCM as Secretary. The first meeting was held at the office of the Martin and Burn in Mission Row - 'to promote study, research and dissemination of knowledge of Statistics'. In India, the Mahalanobis era in statistics started. The first issue of the journal 'Sankhyā' was published in June, 1933, and Tagore sent his blessings to be published in the second issue in 1935 (Fig. 1).

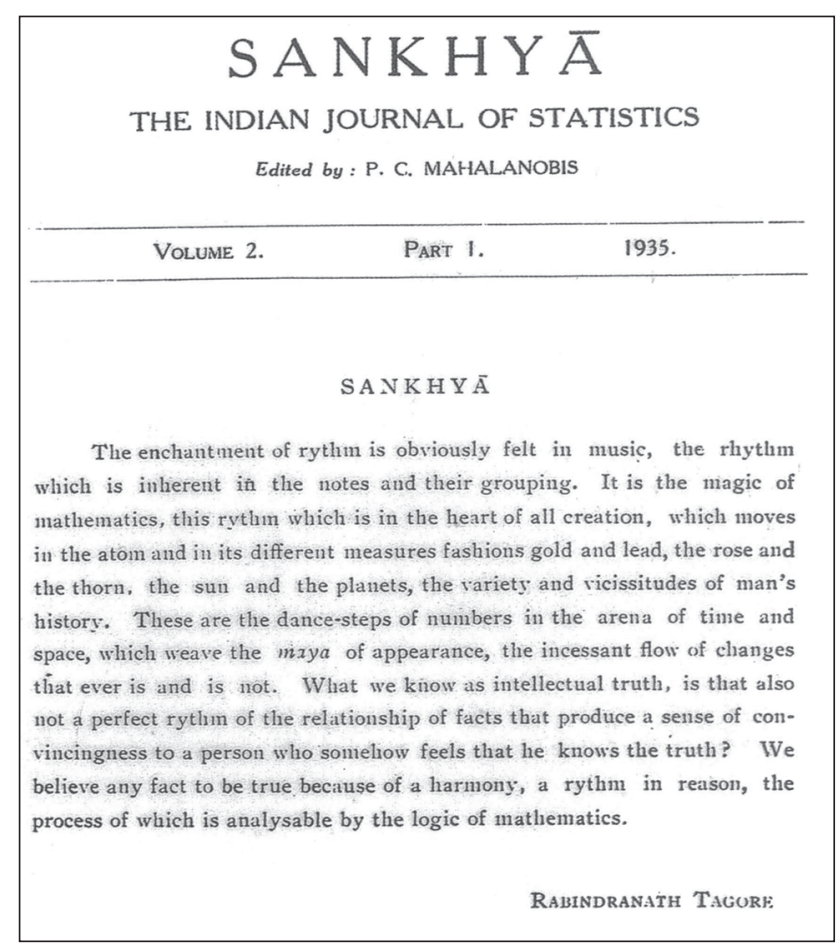

Fig. 1. Rabindranath Tagore on Sankhya

It must be mentioned here that PCM could gather a number of devoted scholars to work with him in the new field of statistics. Subhendu Sekhar Bose (Physics pupil of PCM), Sudhir Kumar Banerjee and Harish Chandra Sinha (Economics teacher of Calcutta University) played important roles. 
Eminent mathematicians R C Bose and Samarendra Nath Roy also joined ISI and collaborated with PCM with 'Mahalanobis Distance' work. However both left for USA in 1950s and left their imprint in the field of statistics.

C R Rao was in the first batch of PG students in Statistics in 1941 and he was in ISI for thirty years, managing affairs when PCM was away.

\section{PCM's election as Fellow to the Royal Society}

PCM's contribution to Statistics is the (i) $\mathrm{D}^{2}$ - distance or Mahalanobis distance for multivariate analysis and (ii) Large scale sample surveys for agricultural experimentation. It was in 1945, he was elected as FRS, joining the select band of Indian Scientists attaining this recognition. Amongst his proposers were E J Russel, R A Fisher, Birbal Sahni and S S Bhatnagar (EC/1945/ 14) (Fig. 2). It will not be out of context here to mention that amongst his colleagues and friends, Ramanujan became FRS in 1918, Saha (1927), S N Bose (1958), C R Rao (1967).

\section{PCM and 2 ${ }^{\text {nd }}$ Five Year Plan: the Nehru Connection}

There were many catalysts to bring PCM to the field of economic planning. In the early

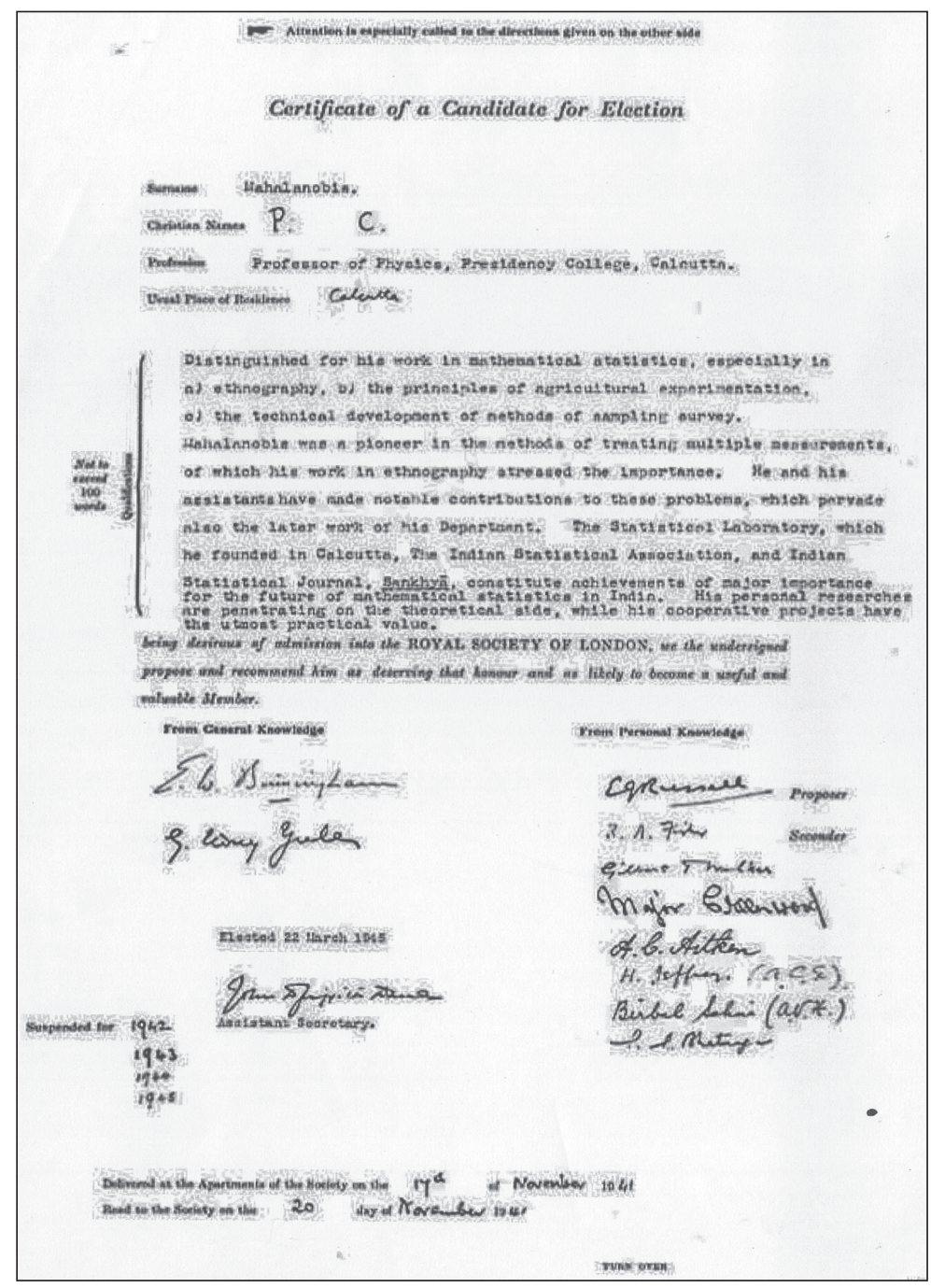

Fig. 2. FRS Citation of Prasanta Chandra Mahalanobis 
years of Indian National Congress, the National Planning Committee was conceived by Netaji Subhas Chandra Bose and M N Saha and PCM was asked to write a statistical supplement to the report. We have on record Nehru's visit to ISI in 1946. After independence, the Planning Commission was formed in 1950 and Mahalanobis was appointed the Hony. Statistical Adviser to CSO in 1951. It was then, with Pitambar Pant, Chief of Perspective Planning Division, Govt. of India and C Deshmukh, Financial Adviser to Govt. of India involved PCM in framing the draft $2^{\text {nd }}$ Five Year Plan of India. The draft which utilised 2 sector and 4 sector models of Operations Research was approved and the $2^{\text {nd }}$ Five Year Plan was put into operation. PCM since then, is hailed as the father of the 5 year plan in India, in which rapid industrialisation was given more importance, as the critiques tell now.

\section{Baranagore Campus \& International Networking}

PCM brought many eminent persons including several nobel laureates. In the meantime Indian Statistical Institute got its new campus on B T Road in Baranagore in 1950s and in 1959 the Parliament enacted the ISI Act in Parliament by declaring it an Institute of National Importance. The list of visitors to ISI includes, R A Fisher, W A Shewhart, Blackett, Joliot and Irene Curie, Paul Dirac, R Firsch, Tinbergen, Kolmogorov, Norbert Weiner, Joan Robinson, Charles Bettelheim, J D Bernal, Niels Bohr, Hotelling, G Taguchi, Ho-ChiMinh, Chou-En-Lai, Che Guevara, J K Galbraith, Milton Freidman, JBS Haldane and many more. Some came for conferences, most gave lectures, some were guests at convocations and some stayed for years (J B S Haldane). All added to the fame of ISI. It must also be mentioned here that both $\mathrm{M}$ N Saha and S N Bose (old colleagues of PCM) were closely associated with ISI work, S N Bose becoming Vice-President for sometime (Fig. 3).

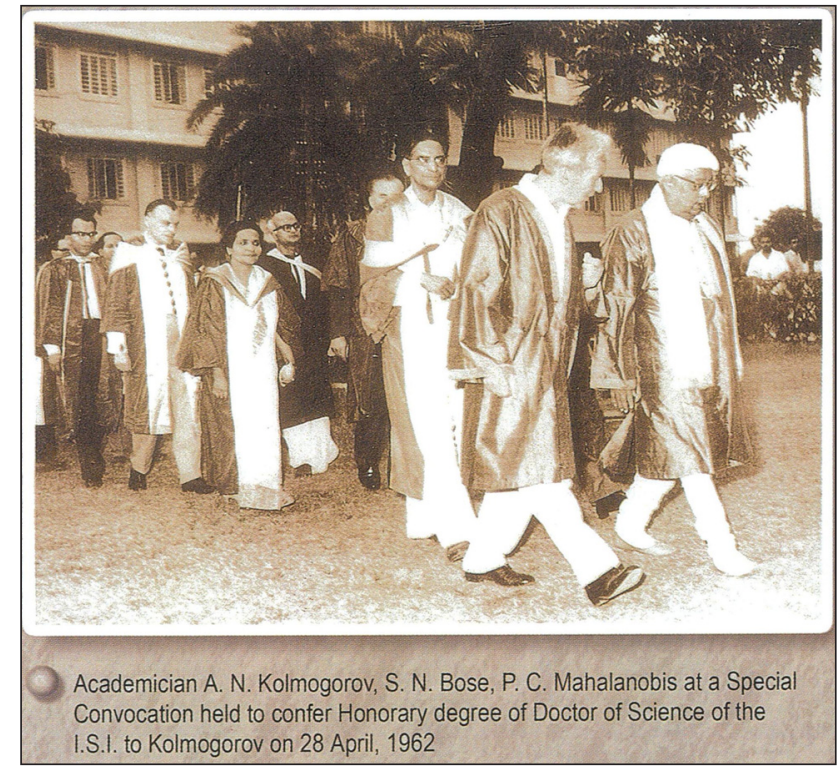

Fig. 3. Special Convocation of ISI held to confer Doctor of Science to A N Kolmogorov, 1962.

\section{Awards and Laurels received by PCM}

Some of the awards/laurels bestowed upon PCM include Chairman, United Nations Statistical Commission (1954-58); President, Indian National Science Academy, INSA (1957); Honorary Doctorate, Calcutta University (1957) and Padma Vibhushan from Govt. of India (1968).

\section{Conclusion}

PCM passed away on $28^{\text {th }}$ June, 1972. However, the journey of ISI continues. PCM's birthday 'June 29' is celebrated as 'Statistics Day' in India. The dream of PCM of considering statistics a 'Key Technology' has come true. ISI now has branches spread all over India. The Delhi, Bangalore and Hyderabad Centres are flourishing to attract young persons in the discipline of Statistics.

\section{BiBLIOGRAPHY}

Anderson, R S. Nucleus and Nation : Scientist, International Networks and Power in India, The University of Chicago Press, 2010. 
Citation of F.R.S. of Prasanta Chandra Mahalanobis - Ref. No.EC/1945/14 of Royal Society Archives (Royal Society Archives accessed on 10.03.2018).

Ghosh, J; Maiti, P and Bera, A. Indian Statistical Institute : Numbers and Beyond, Science in Modern India, ed. Uma Dasgupta, Pearson, 2011.

Mahalanobis, A. Prasanta Chandra Mohalanobis, National Book Trust, India, 1983.

Mahalanobis, Prasanta Chandra, Rabindranath, ed. Uma Dasgupta, Ananda Publishers, Calcutta, 2002 (Bengali).

Mahalanobis, P C. My friendship with Ramanujan in England, Current Science., 65.1 (10 July, 1993).

Mahalanobis, P C. On large scale Sample Surveys, Philosophical Transactions of the Royal Society of London, B-231 (1944): 329-451.

Mahalanobis, P C. The Foundations of Statistics, Dialectica, $8.2(15.06 .1954)$.

Pal, Prasantakumar (ed). Dear Prasanta - Rabindranath PCM Letters (Bengali), West Bengal Bangla Academy, 2005.

Rao, C R. Prasanta Chandra Mahalanobis, Current Science, 65.1 (1993).
Rao, C R. Statistics must have a purpose, Sankhya, The Indian Journal of Statistics, 55, Series A, pt.3, (1993): 331-349.

Rao, C R. Prasanta Chandra Mahalanobis (1893-1972), Biographical Memoirs of the Fellows of the Royal Society, 19 (Dec., 1973): 454-492.

Roy, Krishna, Prasanta Chandra Mahalanobis, Granthatirtha, 2008 (Bengali).

Rudra, Ashok. Prasanta Chandra Mahalanobis, A Biography, Oxford University Press, Delhi, 1996.

Sanyal, H. Prasanta Chandra Mahalanobis : A Biographical Sketch, Sankhyā, The Indian Journal of Statistics, 35, Series A, (1973): 3-11.

Seal, Brajendra Nath. Meaning of Race, Tribe, Nation, InterRacial Problems, G. Spiller (ed.), London, 1911 (accessed from Internet Archieve).

Seal, Brajendra Nath. Memoir on the coefficient of Numbers, a chapter in the Theory of Numbers', Hare Press, Calcutta, 1891; in Proceedings Royal Asiatic Society, 1892, p.397, (accessed through web, Cambridge University notification, March 2011).

The Indian Statistical Institute Act, 1959 (No.57 of 1959). 